http://dx.doi.org/10.30681/23588403v12i01181191

\title{
O TEMPO INABITÁVEL DE QUENTIN COMPSON: UMA ANÁLISE DA TEMPORALIDADE IMPRECISA EM THE SOUMD AND THE FURY DE WILLIAM FAULKNER
}

Data de recebimento: 02/11/2017

Aceite: 15/12/2017

Yasmim Naif Amin Mahmud Kader (UFSM) ${ }^{1}$

Resumo: O tempo sempre esteve como objeto de análise no campo da literatura, levantando questionamentos e discussões desde os tempos primórdios. Mas o que é o Tempo?, perguntou Moises (2006) ao estudar o tema e ressaltar que o tempo no romance é complexo. Nessa perspectiva, tem-se por intuito analisar o tempo dentro do livro The Sound and The Fury de William Faulkner, publicado em 1929, no viés narratológico. A discussão focar-se-á no personagem de Quentin, narrador do segundo capítulo da obra, que, incapaz de vencer o tempo, suicida-se. Para o desenvolvimento do trabalho, será usado os estudos de Genette (1995) e Richardson (2012) a respeito, respectivamente, das anacronias e unnatural narratives, além de outros teóricos que discutam o tempo na literatura e na obra de William Faulkner.

Palavras-chave: Tempo. Anacronias. Quentin. Temporalidade Imprecisa. William Faulkner.

Abstract: Time has always been an object of analysis in the field of Literature, raising questions and discussions since the earliest times. But what is Time?, asked Moisés (2006) analyzing the theme and emphasizing that time in novel is complex. In this perspective, the article aims to analyze the time in The Sound and The Fury by William Faulkner, published in 1929. The discussion will focus on Quentin's character, who narrates the second chapter of the book, and someone who, being unable to deal with time, drowns himself. For the development of the work, it will be used the studies by Genette (1995) and Richardson (2012) that are, respectively, about anachronism and unnatural time, as well as other studies that discuss time in Literature and William Faulkner's work.

Key-words: Time. Anachronism. Quentin. Conflated Temporality. William Faulkner.

\section{Introdução}

"A literatura pode muito", afirmou o escritor Tzvetan Todorov ao responder o questionamento "o que pode a literatura?" em seu livro A Literatura em Perigo escrito em 2006; e, por conseguinte, afirmou que a mesma é "pensamento e conhecimento do mundo que vivemos, $[\ldots]$ a realidade que a literatura aspira compreender é $[. .$.$] a experiência humana" (p.$

\footnotetext{
${ }^{1}$ Mestranda em Estudos Literários pela Universidade Federal de Santa Maria (UFSM), na cidade de Santa Maria - RS, Brasil. Bolsista da Coordenação de Aperfeiçoamento do Ensino Superior (CAPES). E-mail: yasmim.kader@gmail.com
} 


\section{Revista de Estudos Acadêmicos de Letras}

77, 2006). É nessa perspectiva que a literatura, com suas possibilidade e características como o tempo, o espaço ou as personagens que nela vivem -, ganha atenção de muitos estudiosos. Há nela um leque de possibilidades intermináveis: são inúmeras as análises e discussões sobre obras cânones, seus temas e interpretações que se diferenciam ao longo dos séculos.

Nesse sentido, entre tantos assuntos que o texto literário inspira, com o respectivo trabalho, tem-se como pretensão discutir a questão do tempo dentro do segundo capítulo do livro The Sound and The Fury do escritor William Faulkner. Publicada em 1929, a obra é composta por quatro capítulos sem apresentar uma ordem cronológica em relação as vozes de três irmãos e a empregada da família: Benjamin, personagem com deficiência mental incapaz de reconhecer a passagem do tempo; Quentin, que luta para parar o tempo e é derrotado; Jason Compson, o qual abandona os códigos de honra da família relacionados ao Old South e se apega ao novo tempo ou ordem social que aflora no contexto vivido; e, por fim, Dilsey (é pertinente lembrar que o capítulo dela é o único narrado através da voz de um narrador onisciente), a empregada que apresenta uma outra relação com a passagem do tempo. É através do conjunto dessas vozes narrativas que a decadência da família Compson é contada.

O segundo capítulo é narrado por Quentin Compson, o filho de uma família aristocrata empobrecida. No apêndice do livro, o personagem é descrito como alguém que "amava a morte mais do que tudo, amava só a morte, amava e vivia sempre a antegozar a morte de modo deliberado e quase pervertido" (FAULKNER, 2015, p. 303), assim, cometendo suicídio. Apesar desse sentimento obsessivo com a morte, o personagem demonstra sensibilidade para com alguns membros de sua família, uma vez que comete o ato após o ano letivo em Harvard, "para não desperdiçar o dinheiro da anuidade paga de antemão" (FAULKNER, 2015, p. 304) que fora custeado com a venda de um pedaço de terra pertencente aos Compsons. Lugar esse que era "a única coisa, além da referida irmã [Caddy] e da visão do fogo, que seu irmão caçula [Benjy], idiota de nascença, amava." (FAULKNER, 2015, p. 304).

Nessa perspectiva, é nosso interesse estudar a progressão do tempo no segundo capítulo da obra de Faulkner, buscando verificar como ela ocorre, uma vez que é possível perceber uma instabilidade temporal na narrativa veiculada por Quentin. Para o desenvolvimento do artigo, introduziremos uma contextualização do texto de William Faulker, The Sound and The Fury, ancorada nas palavras do próprio autor em relação ao livro. Por conseguinte, faremos uma discussão sobre o tempo de modo mais abrangente na literatura, 


\section{Revista de Estudos Acadêmicos de Letras}

usando as discussões de Moisés (2006). Num segundo momento, apresentaremos as teorias de Genette (1995) e Richardson (2012) sobre, respectivamente, anacronias e temporalidades imprecisas na Literatura. Em seguida, faremos uma relação dessas teorias com Warren (1996) para, então, analisar o tempo em William Faulkner.

Por último, usaremos a teoria para analisar o capítulo de Quentin Compson, buscando compreender como o fluxo temporal se dá na narração do personagem, se é possível identificar anacronias no texto. A partir disso, finalizaremos apresentando resultados parciais deste estudo em andamento.

\section{Referencial teórico}

Mas o que é tempo? Foi com essa questão que Moisés (2006) iniciou seu capítulo sobre o tempo no livro Criação Literária. O autor menciona que, diferente dos gêneros conto e novela - porque o "tempo ali obedece quase um esquema único, o do calendário" (2006, p. 180) -, a questão no romance é complexa. Outra pergunta, então, cabe aqui: por que o romance suscita o problema do tempo? A resposta parece simples: porque, de acordo com Moisés (2006), o romancista é o senhor do tempo e do espaço no qual a vida das personagens se realiza; e, "em um dia de leitura podemos viver anos e anos de existência das personagens de um romance" (Simões 1944, p. 14 apud Moisés, 2006, p. 181). O tempo, desse modo, é sempre arquitetado a maneira do romancista de forma que seja produzido uma humanidade no interior do romance.

Moisés (2006) cita três categorias de tempo dentro do romance, o psicológico, o histórico e o metafísico, mas o que nos interessa para o desenvolvimento do artigo é o tempo psicológico. De acordo com o autor, tal categoria se caracteriza por um aglomerado de acontecimentos imprecisos que se separam ou se fundem, confundindo o passado com o presente, tempo este que ocorre na mente do personagem. Por ser um tempo que varia em cada indivíduo, por ser interior, está associado com a memória. Dessa forma, "enquanto memória, [...] corresponde à memória involuntária” (2006, p. 202), nomeada assim por “desenterrar" o passado sem nenhum aviso prévio, transformando o que era passado em presente da narrativa.

Outro teórico que também discute a perspectiva do tempo na literatura é Genette (1995) no livro Discurso da Narrativa. O autor explica o tema em três categorias: ordem, duração e frequência. Importa-nos, porém, somente as discussões sobre a ordem para a análise do capítulo. Sobre isso, Genette (1995) menciona que essa categoria é a relação entre a ordem 


\title{
Revista de Estudos Acadêmicos de Letras
}

temporal dos eventos da história e a ordem da sua disposição na narrativa. O estudioso nos apresenta às anacronias, as quais se referem às alterações na ordem das "disposições dos acontecimentos (...) temporais no discurso narrativo com a ordem da sucessão desses mesmos acontecimentos (...) na história" (GENETTE, 1995, p. 33). Nesse sentido, o narrador pode evocar acontecimentos e informações posteriores (prolepse) ou anteriores (analepse) dentro da narrativa primeira (a qual seria o eixo principal da história). Logo, toda a discordância de tempo (e deve-se pensar o tempo da história contada e a organização temporal dessa história) será levada à anacronia.

Contudo, é importante ressaltar que o próprio Genette menciona que seus estudos sobre tempo podem provocar contradições com algumas narrativas específicas. Isso é reafirmado por Richardson (2011) ao mencionar que:

\begin{abstract}
"There is no question that Genette's account is generally adequate to describe the temporality of most nonfictional narratives, of the great majority of works of realistic fiction, and of much modernist fiction. [...] However, these categories do not work if applied to many late modernist and postmodern text, since they are predicated on distinctions that experimental writers are determined to preclude, deny or confound." (RICHARDSON, 2011, p. 48). ${ }^{2}$
\end{abstract}

Richardson (2011) inicia o quarto capítulo do livro Unnatural Narratives, mencionando o conceito padrão dos estudos de Genette - ordem, duração e frequência - e afirmando que muitos dos textos modernos e pós-modernos podem não se aplicar as definições dadas por ele. Richardson afirma que as noções genetianas de "frequency as well as his conception of story presupposes the existence of a fixed, retrivable, noncontradictory sequence of events" ${ }^{\prime 3}$ (RICHARDSON, 2011, p. 49), algo que os escritores pós-modernos não fazem ou providenciam. Para tentar explicar essas narrativas que fogem dessas teorias, Richardson menciona seis categorias temporais principais: (I) Circular; (II) Contradictory; (III) Antinomic; (IV) Differential; (V) Conflated; e (VI) Dual or Multiple.

A primeira, Circular, refere-se à narrativas que, ao invés de terminarem, recomeçam. São histórias que se movem em círculo, sempre de volta ao início, repetindo-se infinitamente.

\footnotetext{
${ }^{2}$ Não há dúvidas que os estudos de Genette são geralmente adequados para descrever a temporalidade da maioria das narrativas não-ficcionais, da grande maioria das obras de ficção realista e de muitas ficções modernas. No entanto, essas categorias não funcionam se aplicadas a muitos dos textos modernos e pósmodernos, uma vez que elas se baseiam em distinções que os escritores destes períodos estão determinados a impedir, negar ou confrontar. (Tradução nossa)

${ }^{3}$ Frequência, bem como as concepções de história, pressupõem a existência de uma sequência de eventos fixa, recuperável e não contraditória. (Tradução nossa)
} 
A segunda, Contradictory, inclui histórias que são auto-contraditórias. Para exemplificar, Richardson (2011) menciona que "a man may have died in 1956 or he may have died in 1967, but he cannot have died in 1956 and 1967"^4 (RICHARDSON, 2011, p. 48), ou seja, versões incompatíveis e irreconciliáveis não estabelecidas, o que contradiz a noção de frequência de Genette. Por conseguinte, temos as Antinomic, na qual narrador e leitor se movem prospectivamente no tempo, mas em sentido inverso. A Differential, em que um tempo é sobreposto ao outro, Richardson (2011) cita o exemplo de personagens que envelhecem mais rápido que as demais personagens.

A quinta categoria, Conflated, é a das narrativas em que "diferent temporal zones fail to remain distinct, and slide or spill into one another"5 (RICHARDSON, 2011, p. 50). Desse modo, tempos diferentes, passado e presente, se cruzam e se misturam, confundindo o leitor sobre a distinção entre eles. A análise de Genette (1995) sobre frequência e história teria contradições em reconhecer o que é e não é o mesmo acontecimento. Por fim, a Dual or Multiple, refere-se a histórias com diferentes linhas temporais no mesmo enredo, por mais que elas comecem a terminem no mesmo momento. Importa-nos, então, a quinta categoria disposta por Richardson (2011), Conflated, traduzida por nós como imprecisa, a qual viremos a discutir relacionada com o livro The Sound and The Fury durante a análise.

\section{O tempo em William Faulkner}

O tempo nos trabalhos de William Faulkner é quase uma entidade: seus personagens sempre estão permeados com essa questão, obcecados com o tempo e a passagem deste. Nas obras do autor, o tempo é ser - e não apenas um mecanismo da condição humana ou mundana. Mas não em um sentido positivo: o tempo em Faulkner pode ser considerado um inimigo na visão de seus personagens. Quentin, por exemplo, em The Sound and The Fury, ansiava em parar o tempo, mas, sendo este um ser e não condição, a única alternativa do personagem foi o suicídio, o modo que ele encontrou para impossibilitar o avanço dos ponteiros do relógio. Ao longo da narrativa dele, é possível encontrar um sentimento de aversão e, contraditoriamente, obsessão: embora desejasse escapar do tempo, esquecê-lo,

\footnotetext{
4 “Um homem pode ter morrido em 1956 ou em 1967, mas ele não pode ter morrido em 1956 e 1967” (Tradução nossa).

${ }^{5}$ Diferentes zonas temporais falham em permanecer distintas ou se misturam e se confundem umas as outras" (Tradução nossa).
} 
Quentin, durante seu capítulo que ocorre em apenas um dia, está sempre preocupado em saber que horas são:

\begin{abstract}
"Would you mind telling me if any of those watches in the window are right?" He held my watch on his palm and looked up at me with his blurred rushing eye. "I made a bet with a fellow," I said. "And I forgot my glasses this morning." "Why, all right," he said. He laid the watch down and half rose on his stool and looked over the barrier. Then he glanced up at the wall. "It's twen--" "Dont tell me," I said, "please sir. Just tell me if any of them are right." (FAULKNER, 1984, p. 84)
\end{abstract}

Desse modo, o tempo está intimamente ligado com o passado, presente e futuro das narrativas do autor. Há em Faulkner uma dificuldade de aceitar o presente de modo que não haja futuro, somente passado. Ademais, o passado não é um passado temporal que apenas pode ser lembrado (POUILLON, 1966, p. 80), mas algo aqui e agora. Se o passado é o único "presente" que as personagens têm, logo não há futuro possível. Em The Sound and the Fury há a sensação de que a narrativa não avança; e se avança, é para trás, para o passado. Nunca nos é dado evidências de que as personagens têm um futuro, mesmo que haja, como no caso de Sanctuary, uma pequena progressão de eventos.

Em The Sound and The Fury, porém, não há uma transgressão: a narrativa é narrada por quatro personagens, mas que ocorre apenas em um dia (embora sejam dias distintos para cada narrador). A narração de Benjamin é datada em 7 de abril de 1928, mas composta por anacronias que a faz retornar à um passado distinto; a de Quentin ocorre em 10 de junho de 1910, enquanto a de Jason e Dilsey, respectivamente, 6 e 8 de 1928. Pensando em uma linearidade temporal, teriam a estrutura de: Quentin, Jason, Benjamin e Dilsey, algo semelhante ao que Genette faz ao colocar a enunciação da narrativa de Proust em ordem organizada. Contudo, tanto na narrativa de Benjamin e Quentin, os eventos se confundem na mesma linha temporal, levando o leitor a se perguntar o que é presente ou passado.

Embora todos os capítulos do texto de William Faulkner possuam material para discussão do tempo e das anacronias, nos focaremos em Quentin Compson, o segundo capítulo da narrativa, para analisar a questão temporal e dissertar o modo que o personagem refrata presente e passado.

\title{
3.1 O tempo para Quentin Compson
}


O episódio de Quentin Compson é relatado em um único dia por um Fluxo de Consciência embaralhado e se passa na data de 2 de junho de 1910, sendo essa a narrativa primeira onde as anacronias acontecem. Resumidamente, o capítulo trata da angústia do personagem que não vê sentido no tempo presente e seu suicídio iminente. No entanto, há muito mais para investigar em Quentin do que a simples vontade de tirar a própria vida. No capítulo de Benjamin, o primeiro da obra, não há uma definição clara de quem o personagem Quentin é - muitas vezes ele é referido por ele ou ela na narrativa: 'ele' ao se referir ao próprio Quentin Compson, o primogênito da família; 'ela', por representar a filha de Candace, num tempo futuro.

Quentin é o filho mais velho dos Compson, desse modo, sendo o único a ser enviado à Harvard para estudar devido a situação precária da família. Nas primeiras linhas do segundo capítulo, no entanto, podemos identificar uma das referências mais presentes na narrativa do personagem: o relógio, e consequentemente, o tempo. Como mencionado anteriormente na análise, McHaney (2008) ressalta que cada irmão - Benjamin, Quentin e Jason - possuem um problema com a questão do tempo. Quentin, por exemplo, nas palavras do autor, "wishes to stop [time]", (2008, p. 167).

A introdução do capítulo, por exemplo, nos remete a esse tema e sua importância ao longo da narrativa: na segunda linha, Quentin, ao acordar, tem a consciência de que "[he] was in time again, hearing the watch"7 (FAULKNER, 1984, p. 76). A palavra watch, traduzida como relógio, desencadeia um fluxo de consciência que o faz lembrar de um dado momento em seu passado em que o discurso do pai sobre o absurdo de toda a experiência humana, sobrepõe a sua consciência.

"I give you the mausoleum of all hope and desire; it's rather excruciating-ly apt that you will use it to gain the reducto absurdum of all human experience which can fit your individual needs no better than it fitted his or his father's. I give it to you not that you may remember time, but that you might forget it now and then for a moment and not spend all your breath trying to conquer it. Because no battle is ever won he said. They are not even fought." (FAULKNER, 1984, p. 76).

Em seguida, a narrativa prossegue com Quentin quebrando o relógio, embora consiga ainda ouvir o tique-taque em sua cabeça. Há, em seu discurso, um sentimento contraditório em relação ao tempo, uma vez que, logo após quebrar o relógio, ele o leva para o conserto. Um

\footnotetext{
6 “Deseja parar o tempo." (Tradução Nossa).

7 "Ele estava no tempo de novo, ouvindo o relógio." (Tradução Nossa).
} 


\title{
Revista de Estudos Acadêmicos de Letras
}

dos motivos que pode explicar essa obsessão do personagem com o tema seria o passado. Para explicar isso, Pouillon (1966) menciona que "Faulkner's people are real only in their past" (POUILLON, 1966, p. 86), ressaltando que o passado, para personagens como Quentin, “does not know itself as memory, does not know itself as anything but the sense of reality", (POUILLON, 1966, p. 79); ou seja, o passado em Faulkner é a realidade desses personagens e é transformado em presente.

Se pensarmos no que propõe Genette (1995), a narrativa de Quentin segue com a evocação de analepses involuntárias que se intensificam com o estado da consciência do personagem. Os acontecimentos anteriores são apresentados quando, no presente, existe ligações com o que aconteceu no passado; e então, a analepse que deveria ser um passado, se torna presente - não da história, mas do personagem.

Nas primeiras páginas da narrativa, enquanto Quentin prepara duas cartas para o pai, sua atenção se foca em uma sombra na varanda quando, de repente, uma anacronia acontece. Nessa analepse, Quentin narra os momentos em que vê, no passado, uma outra sombra. Contudo, essa anacronia sequer é finalizada ao retornar abruptamente para um presente distinto daquele evocado pelo personagem.

\begin{abstract}
"The shadow hadn't quite cleared the stoop. [...] It moved almost perceptibly, creeping back inside the door, driving the shadow back into the door. Only she was running already when I heard it. In the mirror she was running before I knew what it was. [...] Father had a V-shaped silver cuirass on his running chest Shreve said "Well, you didn't... Is it a wedding or a wake?" "I couldn't make it," I said." (FAULKNER, 1984, p. 81-82).
\end{abstract}

A parte em itálico seria a analepse, interrompida de repente pela narrativa primeira que, diferente de como estava antes da anacronia, avançou como se aquele passado mentalizado por Quentin fosse transformado em presente, e o que ele presenciou no presente, fosse encoberto pelo passado. Apesar disso, até esse ponto, a narrativa de Quentin ainda parece ter uma ordem. Contudo, nas páginas seguintes, isso se perde. Pouco a pouco, a narração do personagem começa a se embaralhar, não sendo mais possível distinguir as anacronias, se temos uma analepse ou uma prolepse. Essa "transformação" de passado em presente segue acontecendo como no respectivo fragmento:

\footnotetext{
8 “As personagens de Faulkner são reais apenas em seus passados" (Tradução Nossa).

9 "Não se reconhece como memória, não se reconhece como nada além da própria realidade" (Tradução Nossa).
} 


\section{Revista de Estudos Acadêmicos de Letras}

"There was no nigger in this car, and the hats unbleached as yet flowing past under the window. Going to Harvard. We have sold Benjy's He lay on the ground under the window, bellowing. We have sold Benjy's pasture so that Quentin may go to Harvard a brother to you. Your little brother. You should have a car it's done you no end of good dont you think so Quentin I call him Quentin at once you see I have heard so much about him from Candace." (FAULKNER, 1984, p. 84)

Na primeira parte da citação, supostamente temos a narrativa primeira, no entanto, com uma anacronia, retornamos ao passado (parte em itálico, como consta no livro) e, de novo, presente, mas não mais o presente que o personagem está, dentro do bonde. Então, outro passado, evocando a lembrança do discurso de alguém dentro da narrativa de Quentin. Aqui, as teorias de Genette (1995) já se tornam contraditórias, sendo pertinente trazer Richardson (2012) para a discussão. Essa mistura de tempos, não mais sendo possível encontrar uma ordem e uma distinção entre eles, dialoga com o que o autor chama de conflated, uma temporalidade imprecisa em nossa tradução.

Para exemplificar essa questão, deve-se pensar na cena, páginas a diante, em que Quentin se desentende com outro estudante no presente; no entanto, o que lemos é a briga que o personagem teve no passado com o amante da irmã. Nessa cena, Quentin insulta o estudante sem ter consciência disso: ele está absorto no passado e não no presente. O passado é a única realidade que o personagem vê, uma vez que "inserted into time, the past was and is therefore past, but inasmuch as it subsists, it is present." ${ }^{10}$ (POUILLON, 1966, p. 80).

Seguindo na narrativa, Quentin acaba encontrando uma menina ao entrar em uma padaria e, percebendo que ela estava sozinha, compra-lhe um pão e a acompanha até a casa da mesma. No entanto, o personagem é mal interpretado e tido como um abusador. É, então, que a partir desse momento Quentin começa a sofrer uma maior desestabilização temporal mais intensa, passado invadindo o presente com uma maior frequência. As narrações no passado emergem e encobrem a própria narração do personagem, ficando confuso para o leitor como diferenciar o contexto.

No entanto, como antes mencionado, William Faulkner utiliza o itálico para delinear o passado do presente. Seria possível, dessa forma, identificar ambos, mas o problema em questão é que esse passado que surge em itálico nunca (ou quase nunca) é o mesmo que apareceu duas linhas antes. Sendo, assim, impreciso, como é o caso em:

"No," Shreve said. Running the beast with two backs and she blurred in the winking oars running the swine of Euboeleus running coupled within how

\footnotetext{
10 "Inserido no tempo, o passado foi e é passado, mas enquanto existe, ele é presente" (Tradução nossa).
} 


\section{Revista de Estudos Acadêmicos de Letras}

many Caddy. "Neither did I," Spoade said. I dont know too many there was something terrible in me terrible in me Father I have committed Have you ever done that We didnt we didnt do that did we do that" (FAULKNER, 1984, p. 148)

Nesse fragmento, enquanto as pessoas conversam com Quentin, o personagem apenas os observa, prestando atenção apenas no tempo que emerge em sua narrativa, um tempo que, na primeira parte, narra alguém correndo, na segunda, alguém conversando. Ou seja, tempos distintos que surgem e se misturam, incapazes de encontrar uma delimitação. É quase impossível para o leitor dizer em quais momentos tais temporalidades pertencem, levando-nos as teorias de Richardson (2011) sobre as narrativas conflacted.

O segundo capítulo de The Sound and The Fury nos faz ter a impressão de que a própria narrativa se distância do que se entende por tempo. Ele anula as teorias de Genette (1995), não sendo possível diferenciar as analepses e prolepses do texto, confundindo, assim, o leitor quanto as noções de presente e passado. Desse modo, a argumentação de Richardson (2011) nos é pertinente no que diz respeito a temporalidade conflated, uma vez que ela se aproxima de nossa tentativa de entender o tempo na narração de Quentin Compson. O capítulo dele segue nessa mesma estrutura, de um tempo impreciso, de um passado que é presente para o personagem.

Para finalizar, no início do capítulo, há uma menção da expressão reducto absurdum, a qual remete ideia de que se seguirmos por um caminho lógico, alcançaremos um resultado absurdo. O termo nos é pertinente agora: o reducto absurdum na vida de Quentin seria o suicídio - a única forma que o personagem encontra de concretizar seu desejo: aniquilar o tempo presente onde não consegue encontrar sentido.

\section{Considerações Finais}

O tempo no monólogo interior de Quentin é um símbolo de suma importância ao longo da narrativa. É possível percebemos que o personagem está constantemente tentando fugir do tempo presente, o qual não aceita, retornando, assim, o passado. Disso, é possível concluir que, utilizando as teorias de Genette (1995) com o intuito de entender a progressão do tempo, é impossível encontrar uma ordem dentro da narrativa. O capítulo começa de forma organizada, mas, de repente, somos introduzidos a um ritmo embaralhado de tempos distintos que se misturam e se confundem. 


\section{Revista de Estudos Acadêmicos de Letras}

O que podemos dizer é que, no tempo psicológico de Quentin Compson, impulsionado, nas palavras de Moisés (2006) pela memória involuntária, se torna impreciso, ou conflated (RICHARDSON, p. 50, 2011), no momento em que o personagem expõe o leitor a dois, três ou até quatro tempos dentro da narrativa primeira. Assim, anulando o que Genette (1995) propõem como anacronias. Dessa análise, é possível também dizer que o personagem de Quentin está tão apegado ao que 'era' (passado) que se distancia do que 'é' (presente). Assim, seu desejo pungente de vivificar o passado, único tempo onde o sentido da vida ainda é possível.

\section{Referências}

FAULKNER, William. O Som e a Fúria. Trad. Paulo Britto. São Paulo: Cosac \& Naif, 2015. . The Sound and The Fury. The corrected text. Toronto: Vintage International, 1984.

GENETTE, Gerard. Discurso da narrativa. Alpiarça: Vega, 1995.

MASSAUD, Moisés. A Criação Literária: prosa I. São Paulo: Cultrix, 2006.

MCHANEY, Thomas L. Themes in the Sound and the Fury. In: BLOOM, Harold (Org.).

William Faulkner's The Sound and the Fury. New York: Info base Publishing, 2008, p. 149-180.

POUILLON, Jean. Time and destiny in Faulkner. In: WARREN, R. Penn (Org.). Faulkner: a collection of critical essays. New Jersey: A Spectrum Book, 1966, p. 79-86.

RICHARDSON, Brian. Unnatural Narrative: Theory, History, and Practice. Ohio: Ohio State University Press, 2011.

TODOROV, Tzvetan. A Literatura em Perigo. Trad. Caio Meira. Rio de Janeiro: DIFEL, 2012. 